\title{
Development of A Maintenance Device for Bus-bar PT Voltage Air Switch
}

\author{
Xiang Zhang*, Ying Chen, Gaoxiang Lin and Bifu Qian \\ Wenzhou Power Supply Company of SGCC, Wenzhou, Zhejiang 325000, China \\ Corresponding Email: xiangzju@126.com
}

\begin{abstract}
When PT breaks down, it takes long time of switching operation before maintenance, which seriously delays the restoration time. Based on the principle of multiple circuit, a live replacement maintenance device for PT voltage air switch is proposed. The following aspects are involved in the design of the device: the principle of device, component selection, device's assembly and operation process. Through functional test in simulation substation and on-site installation, it is proved that the failed air switch can be lively replaced by the device without switching operation, which greatly reduces the risk on power grid caused by such faulted air switch.
\end{abstract}

Keywords.Air switch, potential transformer, live replacement, switching operation.

\section{Introduction}

State Grid Corporation of China firmly considers building strong power grid as the development trend $[1,2]$, so taking measures to protect the vulnerable points always remains a crux [3,4].Due to long-term operation in the outdoor terminal boxes, the voltage air switch of bus-bar potential transformer (PT) is prone to appear increasing internal resistance, serious voltage allocation problem and even single-phase or multi-phase interruption. These issues cause a voltage difference; therefore make the voltage acquisition inaccurate. Unbalanced voltage in high level will unlock the compound voltage lockout so that bus protection, transformer protection and line protection act incorrectly which leads to severe consequence [5]. For the maintenance department, the abnormity of the voltage air switch of bus-bar PT requires fast restoration. However, current maintenance procedure needs switching operation of dispatching department and operation department. Only after dropping out the PT can the maintenance of corresponding air switch begin. It is obvious that current time-taking process cannot meet the demand.

Live replacement can be an effective way to solve this problem, and until now seldom relevant reports have been seen. Literature [6] introduces a cabinet tool which can lively replace the DC fuse, but it isn't applicable to compact terminal array of PT. The essay presents a maintenance pedestal, with which maintenance personnel could replace the voltage air switch of bus-bar PT lively. Through the design of principle, device manufacture and system testing, this device complies fully with the requirements, and thus enhances the stability of power grid much further.

\section{Design background}

\subsection{Potential transformer and corresponding air switch}

Potential transformer is an essential element for linear voltage transition [7]. The secondary voltage can be used to calculate, monitor and count for load equipment such as protection equipment, measurement, control devices and metering devices. When the potential transformer voltage air switch in operation emerges short circuit, the strong short current will burn out the potential transformer [7].Therefore, one main air switch is setup in the potential transformer terminal boxes to protect the secondary circuit. Figure 1 shows the secondary circuit of $220 \mathrm{kV}$ bus-bar potential transformer. 


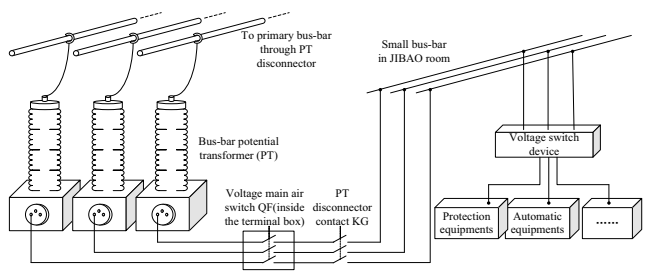

Fig. 1. Secondary circuit of $220 \mathrm{kV}$ bus-bar potential transformer.

\subsection{Traditional maintenance mode}

When the main air switch QF needs urgently replacing for abnormity, traditional maintenance mode has to conduct switching operation in order not to lose the secondary voltage that makes a difference in the reliability of protection devices. The switching operation includes transference of primary equipment and secondary equipment connected with PT to that in adjacent bus-bar, then the PT quits operation.

Take protection main air switch failure of PT in bus-bar I for example: in typical $220 \mathrm{kV}$ double bus-bar main wiring (refer to Figure 2), there are two approaches of switching operation. One is to transfer primary equipment from bus-bar I to bus-bar II so that bus-bar I and its PT quit operation. The other has to close bus-tie circuit breaker, then quit the PT in bus-bar I with the assistance of secondary voltage juxtaposition.

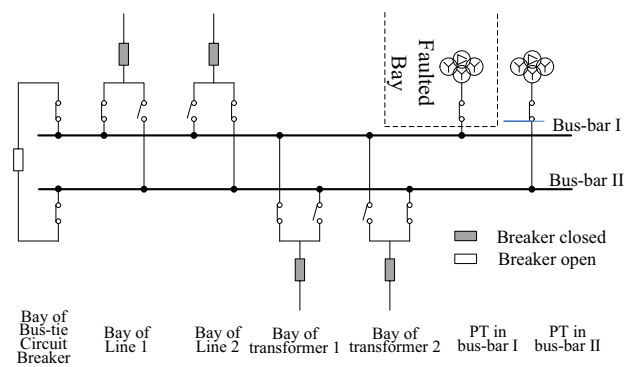

Fig. 2. Typical 220kV double bus-bar main wiring.

Table 1 compares the two switching operations, including equipment numbers, average operation time and risk rank of power grid. It is clear that the time-consuming procedure can't match the demand of timely recovery. Furthermore, it breaches building strong power grid because of the reduced reliability after operation [8].

Table 1. Comparison of the two switching operations.

\begin{tabular}{lll}
\hline No. & Mode One & Mode Two \\
\hline $\begin{array}{l}\text { Switch Operation } \\
\text { Introduction }\end{array}$ & $\begin{array}{l}\text { Operate primary } \\
\text { devices from bus- } \\
\text { bar I to bus-bar II } \\
\text { and quit bus-bar I. }\end{array}$ & $\begin{array}{l}\text { Close bus-tie circuit } \\
\text { breaker, juxtapose the } \\
\text { secondary voltage } \\
\text { and quit the PT in } \\
\text { bus-bar I. }\end{array}$ \\
\hline $\begin{array}{l}\text { Operation Times of } \\
\text { Primary Devices }\end{array}$ & 7 & 2 \\
\hline $\begin{array}{l}\text { Operation Times of } \\
\text { Secondary Devices }\end{array}$ & 0 & 1 \\
\hline Operation Time & 143 mins & 71 mins \\
\hline $\begin{array}{l}\text { Main Wiring Mode } \\
\text { after Operation } \\
\text { Switch Single-bus }\end{array}$ & $\begin{array}{l}\text { Double-bus } \\
\text { juxtaposition }\end{array}$ \\
\hline $\begin{array}{l}\text { Risk Grade of } \\
\text { Power Grid and } \\
\text { Audit Mode }\end{array}$ & $\begin{array}{l}\text { leaders } \\
\text { department } \\
\text { charge } \\
\text { approved by leaders } \\
\text { of company }\end{array}$ & $\begin{array}{l}\text { and and Approved by } \\
\text { leaders of regulation } \\
\text { and control center }\end{array}$ \\
\hline
\end{tabular}


To decrease the impact on power grid that given by maintaining such air switch and to reduce the abnormal voltage time, this essay put forward a live replacement maintenance device for PT voltage air switch. Installing this device under original air switch makes it possible to isolate and replace the main air switch without outage of secondary voltage.

\subsection{Device principle}

The design is based on the principle that reserve protection circuit replaces the abnormal air switch circuit and parallel connecting. The two voltage circuit can realize seamless switching. Circuit one is used on normal operating while circuit two is activated during voltage air switch maintenance as reserve protection. The final maintenance device mainly consists of circuit switch, reserve protection and circuit monitoring modules. Figure 3 shows Schematic of the maintenance device and Table 2 clarifies components in the schematic.

\subsubsection{Circuit switch module}

Circuit switch module includes a 6-set and 2-level MBB rotary switch called K. MBB rotary switch remains a state that connects fore and back contacts when switching [9]. It enables the protection function of secondary circuit to seamlessly switch from normal operating (circuit one) to reserve protection (circuit two) without outage. Six sets of contacts realize the function that switches three-phase voltage in both sides of air switch synchronously. When rotary switch $\mathrm{K}$ is switched to reserve protection, the air switch in normal operating circuit is isolated. Therefore, maintenance personnel can replace the broken-down air switch in safety.

\subsubsection{Reserve protection module}

During isolation of original air switch, the protection function of voltage secondary circuit is provided by reserve protection module $\left(\mathrm{R}_{\mathrm{A}}, \mathrm{R}_{\mathrm{B}}, \mathrm{R}_{\mathrm{C}}\right)$.In the process of maintenance, the voltage circuit can be reliably switched off by reserve protection module when load secondary circuit occurs short circuit and grounding, which avoids short circuit in PT secondary side.

\subsubsection{Circuit monitoring module}

Circuit monitoring module consists of four sets of interphase indicator light, which monitor the voltage condition respectively. It provides direct operation feedback for reliability and safety of circuit switch. Considering reducing the operation power of circuit monitoring module and decreasing the ratio of PT capacity, the device chooses luminous diode of low nominal voltage with biggish circuit resistance.

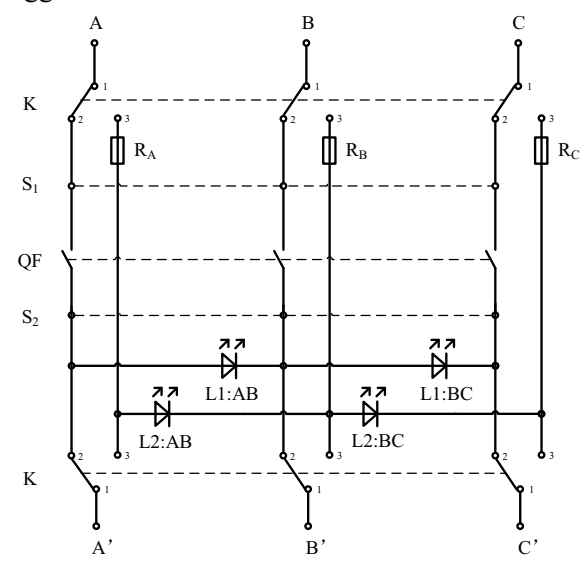

Fig. 3. Schematic of the maintenance device.

Table 2. Components in schematic.

\begin{tabular}{lll}
\hline No. & Symbol & Introduction \\
\hline 1 & QF & Three-phase AC voltage air switch \\
\hline 2 & A、B、C & $\begin{array}{l}\text { Upper port of maintenance device, } \\
\text { connected with three-phase voltage in } \\
\text { secondary side of PT }\end{array}$ \\
\hline 3 & A'、B'、C' & Lower port of maintenance device, \\
\hline
\end{tabular}




\begin{tabular}{lll}
\hline & & $\begin{array}{l}\text { connected with protection equipment, } \\
\text { automatic equipment and so on }\end{array}$ \\
\hline 4 & $\mathrm{~K}$ & $\begin{array}{l}\text { MBB rotary switch, used to switch } \\
\text { voltage circuit }\end{array}$ \\
\hline 5 & $\mathrm{R}_{\mathrm{A}} 、 \mathrm{R}_{\mathrm{B}} 、 \mathrm{R}_{\mathrm{C}}$ & $\begin{array}{l}\text { Overcurrent protection components of } \\
\text { reserve circuit }\end{array}$ \\
\hline 6 & $\mathrm{~S}_{1} 、 \mathrm{~S}_{2}$ & $\begin{array}{l}\text { Contacts connecting air switch QF and } \\
\text { maintenance device }\end{array}$ \\
\hline 7 & $\begin{array}{l}\mathrm{L} 1: \mathrm{AB} \\
\mathrm{L} 1: \mathrm{BC} 、 \\
\mathrm{~L} 2: \mathrm{AB} \\
\mathrm{L} 2: \mathrm{BC}\end{array}$ & \\
\end{tabular}

\subsection{Components' selection}

The physical device is based on schematic. In order to downsize the size, fuse, rotary switch and indicator light are intensively arranged. Three-phased voltage air switch is fixed on the right of the device with normative slot that makes it easier to clearing and wiring as is shown in Figure 4.
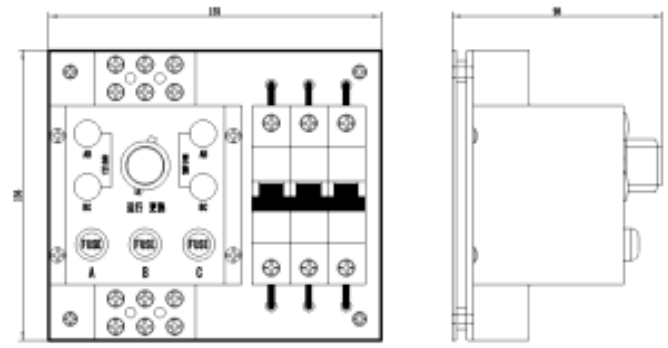

Fig. 4. Design drawing of device.

After confirming the final design drawing of device, correlation test and orthogonality analysis method are used to select component model with the aim of lowest operation power and resistance balance of three-phased voltage circuit. The indicator light in the normal operating circuit is selects as green while the reserve protection circuit red so that it is easily distinguished; The nominal current of ceramic tube fuse matches the trip setting current of voltage air switch. Components' selection is shown on Table 3.

Table 3. Components' selection.

\begin{tabular}{|c|c|c|c|}
\hline Component & $\begin{array}{l}\text { Type and } \\
\text { specification }\end{array}$ & $\begin{array}{l}\text { Quantit } \\
\mathrm{y}\end{array}$ & Size $/ \mathrm{mm}^{3}$ \\
\hline $\begin{array}{l}\text { Rotary fuse } \\
\text { base }\end{array}$ & FH1-13 & 3 & $\varphi 18 * 53.2$ \\
\hline $\begin{array}{l}\text { LED } \\
\text { indicator } \\
\text { light }\end{array}$ & $\begin{array}{l}\text { AC12V } \\
\text { Red }\end{array}$ & 2 & $\varphi 10 * 35$ \\
\hline $\begin{array}{l}\text { LED } \\
\text { indicator } \\
\text { light }\end{array}$ & $\begin{array}{l}\text { AC12V } \\
\text { Green }\end{array}$ & 2 & $\varphi 10 * 35$ \\
\hline $\begin{array}{l}\text { Rotary } \\
\text { switch }\end{array}$ & XB2-BD & 1 & $\varphi 30 * 40$ \\
\hline $\begin{array}{l}\text { Terminal } \\
\text { array }\end{array}$ & 8003 & 2 & $\begin{array}{l}40 * 26 * 2 \\
6\end{array}$ \\
\hline Air switch & $\begin{array}{lr}\text { B6 three- } \\
\text { phase } \\
\text { voltage }\end{array}$ & 1 & $\begin{array}{l}90 * 53 * 7 \\
0\end{array}$ \\
\hline $\begin{array}{l}\text { Ceramic } \\
\text { tube fuse }\end{array}$ & $6 \mathrm{~A} / 250 \mathrm{~V}$ & 3 & $\varphi 6 * 30$ \\
\hline $\begin{array}{l}\text { Metal film } \\
\text { resistance }\end{array}$ & $2 \mathrm{~W} 50 \mathrm{k} \Omega$ & 4 & $\varphi 3 * 9$ \\
\hline
\end{tabular}




\section{Device test and efficiency analysis}

\subsection{Function test}

In the local simulation substation, the group imitates a construction of voltage secondary circuit to test the operation circumstance of circuits switch and air switch replacement.

When it happens one-phase or multi-phase abnormal interruption, the PT/TV breaking detection of protection devices sends out warning signal after judging time, and meanwhile quit the main protection function of distance protection element and direction element [10].

For the commonly used $220 \mathrm{kV}$ protection devices in Wenzhou, Table 4 shows time discrimination of PT/TV breaking in protection devices, from which we can know that CSC-103B developed by BEIJING SIFANG Automation CO.,LTD, and WXH-803A developed by XJ Group Corporation spend the shortest judging time as 1 second.

Table 4. Time discrimination of PT/TV breaking in protection devices.

\begin{tabular}{|c|c|c|c|}
\hline Manufacturer & $\begin{array}{l}\text { Protection } \\
\text { type }\end{array}$ & $\begin{array}{l}\text { Device } \\
\text { type }\end{array}$ & $\begin{array}{l}\text { Time } \\
/ \mathrm{s}\end{array}$ \\
\hline \multirow{3}{*}{$\begin{array}{l}\text { NARI } \\
\text { Protection } \\
\text { Company }\end{array}$} & Line & RCS-931 & 1.25 \\
\hline & $\begin{array}{l}\text { Transform } \\
\text { er }\end{array}$ & RCS-978 & 10 \\
\hline & Bus & RCS-915 & 1.25 \\
\hline \multirow{3}{*}{$\begin{array}{l}\text { BEIJING SIFANG } \\
\text { Automation } \\
\text { CO.,LTD }\end{array}$} & Line & $\begin{array}{l}\text { CSC- } \\
103 \mathrm{~B} \\
\end{array}$ & 1 \\
\hline & $\begin{array}{l}\text { Transform } \\
\text { er }\end{array}$ & CSC-326 & 10 \\
\hline & Bus & CSC-150 & 10 \\
\hline \multirow{3}{*}{$\begin{array}{l}\text { GUODIAN } \\
\text { Nanjing } \\
\text { Automation } \\
\text { CO.,LTD }\end{array}$} & Line & PSL-603 & 1.25 \\
\hline & $\begin{array}{l}\text { Transform } \\
\text { er }\end{array}$ & PST-1202 & 1.25 \\
\hline & Bus & SG-B750 & 10 \\
\hline \multirow{2}{*}{$\begin{array}{l}\text { XJ } \\
\text { Corporation }\end{array}$} & Line & $\begin{array}{l}\text { WXH- } \\
803 \mathrm{~A}\end{array}$ & 1 \\
\hline & $\begin{array}{l}\text { Transform } \\
\text { er }\end{array}$ & $\begin{array}{l}\text { WBH- } \\
800\end{array}$ & 10 \\
\hline $\begin{array}{ll}\text { CYG } & \text { SUNRI } \\
\text { CO.,LTD. } & \\
\end{array}$ & Bus & BP-2B & 9 \\
\hline
\end{tabular}

Figure 5 illustrates the wiring of function test. The voltage sampling circuit of CSC-103B line protection device and maintenance device is constructed in simulation substation. HAOMAI 1600 test device can output simulative threephase nominal voltage of PT secondary side. The result of fifty times air switch replacement tests shows the voltage sampling neither interrupting nor appearing PT/TV warning signal when the device conducts circuit switching. And under the condition of reserve protection circuit, the clearing and wiring of air switch won't influence the sampling.

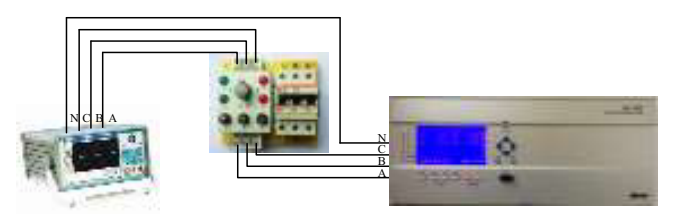

Fig. 5. Wiring of function test.

\subsection{On-site installation and implementation efficiency}

In the $220 \mathrm{kV}$ PT terminal box reconstruction project of one specific $220 \mathrm{kV}$ substation, the maintenance device is installed in the field (refer to Figure 6). The original three-phased AC air switch is replaced by maintenance device, and then placed on the maintenance device. 


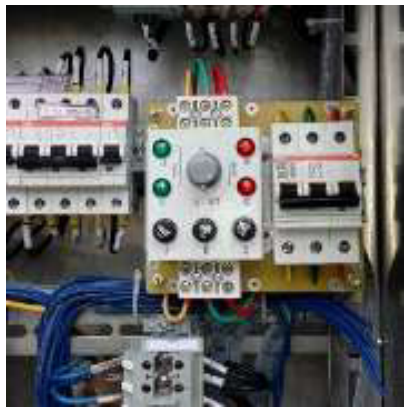

Fig. 6. On-site installation in $220 \mathrm{kV}$ PT terminal box.

Traditional maintenance mode needs switching operation to replace the abnormal air switch, involving nine sections of three departments(refer to Figure 7). With this device, maintenance can take operating personnel's switching operation and despatcher's operation compilation out so that the procedure cut down to five parts (refer to Figure 8); Working timespan decreases from 288.5 mins to 66.5 mins. What's more, operation personnel can take the task of air switch replacement with further implementation of operation-maintenance integration. Having no participation of maintenance department, the procedure can be reduced to less than 30 mins.

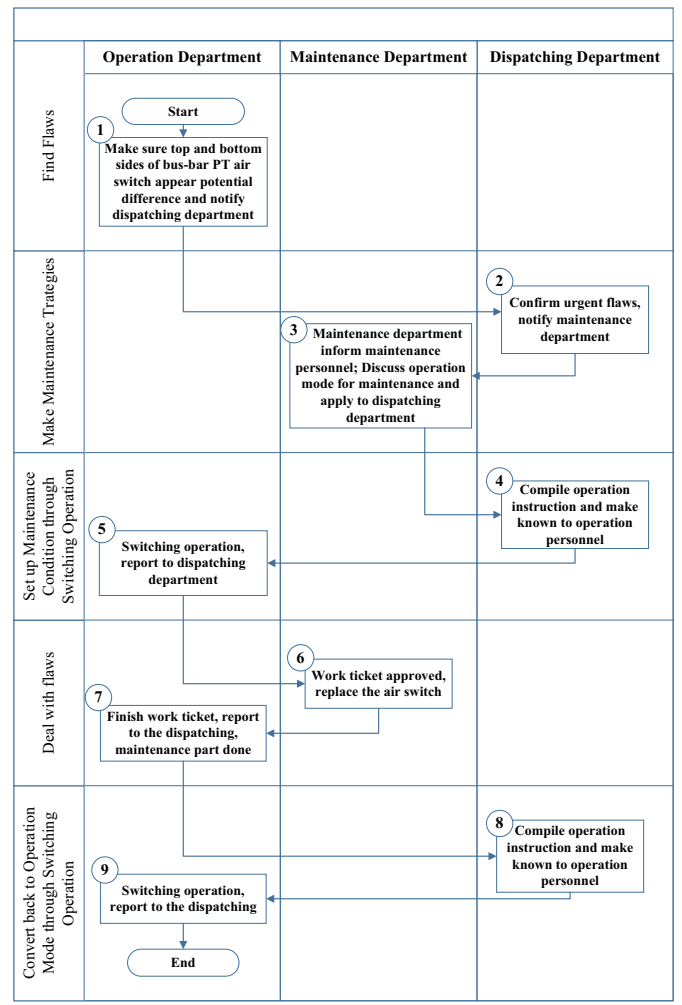

Fig. 7. Swim-lane Flowchart of replacement without maintenance device. 


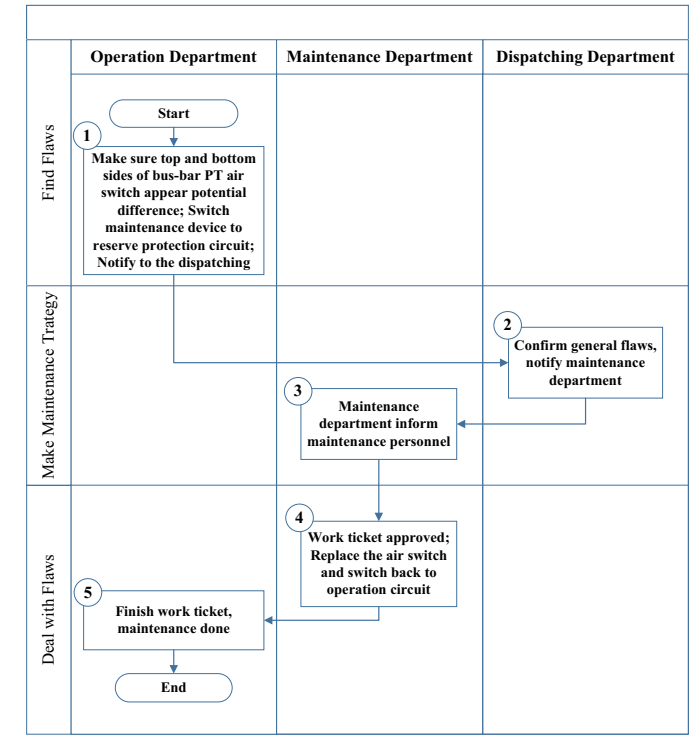

Fig. 8. Swim-lane Flowchart of replacement with maintenance device.

Operation personnel applies reserve circuit to temporarily substitute the faulted air switch, that helps protection voltage recovered at once and changes the grade of flaws from urgency to the general. Moreover, it cuts down the risk taken by switching operation and brings benefits to the stable operation of power grid.

\section{Conclusion}

This essay put forward a new maintenance device for bus-bar PT voltage air switch. Based on the principle of multiple circuit, it applies to replace air switch in different situations of switching operation. The device successfully simplifies work procedure from 9 sections into 5 sections, and the timespan reduces from 288.5 mins to 66.5 mins. It not only increases the efficiency but also tremendously reduces the risk taken by abnormal voltage for stable operation of power grid.

\section{References}

1. Liu Z Y. Smart grid technology. Beijing: China Electric Power Press,1-11(2010).

2. Zhang Dongxia, Yao Liangzhong;Ma Wenyuan. Development strategies of smart grid in china and abroad. Proceedings of the CSEE , 31, 1-14(2013).

3. Liu Z Y. Electric power and energy in China. Beijing: China Electric Power Press, 18-44(2012).

4. Xie Kai, Liu Yongqi, Zhu Zhizhong, et al. The vision of future smart grid. Electric Power, 41, 19-22(2008).

5. Gao Zhongde, Shu Zhihuai, Wang Delin, et al. State grid corporation of protection training materials. Beijing: China Electric Power Press, 411-416(2009).

6. Huang Wei, Zhang Jianghuan, Hu Junhua, et al. Substation DC system fuse Live Replacement. Electric Engineering, 43, 51-52(2015).

7. Mao Jinqing, Zhao Zigang, Ma Jie, et al. Practical technical questions and answers of power system relay protection. Second edition. Beijing: China Electric Power Press, 125-133(2006).

8. Song Xinli, Tang Yong, Bu Guangquan, et al. Full dynamic simulation for the stability analysis of large power system. Power System Technology, 32, 23-28(2008).

9. Wang Quantao, Yao Shujun, Han Minxiao, et al. Solid static transfer switching for duplex feeding. Electric Power Automation Equipment, 30, 67-70(2010).

10. Yuan Zhian. Principle and application of loss-of-potential logic. Electric Power Automation Equipment, 29,147150(2009). 